DRAG POLAR FOR COMBAT AIRCRAFT

\author{
SATHISH KUMAR SUNNAM ${ }^{1}$, CH. TEJO KAMAL ${ }^{2} \&$ L SUSHMA $^{3}$ \\ ${ }^{1}$ Scientist-D, ADA, DRDO, Telangana, India \\ ${ }^{2,3}$ Department of Aeronautical Engineering, Mallareddy College of Engineering and Technology,
}

Secunderabad, Telangana, India

\begin{abstract}
For combat aircraft design, the drag estimation plays a vital role for having better flight performance with less fuel consumption. The drag reduction has become a prime importance to military and civilian aircraft, because for an increase of one Count (i. e., $\square C D=0.0001$ ) necessitate for $80 \mathrm{~kg}$ reduction in weight for attaining the same performance. Therefore to persists a better performance of combat aircraft it is required an accurate prediction of drag at subsonic and supersonic speed. In supersonic speed, the drag becomes more essential due to shock wave formations which causes a wave drag.

Computational Fluid Dynamics (CFD) techniques have been improved over the last decade for an accurate prediction of the drag at subsonic to supersonic speeds. The evaluation of drag assists in improving the aircraft design and performance. In this study, drag polar on combat aircraft with clean and stores configuration has been assessed for drag estimation. Initially, the study has been carried on body of revolution (BOR) to quantify the wave drag contribution between aircraft clean and stores configuration. Hence, BOR provides a rough estimation of drag for a given aircraft area-distribution in minimum turn-around time, as a consequence improving the aircraft design and performance through Aera-distribution. Moreover, the $\mathrm{N}-\mathrm{S}$ simulation has been studied on $3 D$ aircraft for drag polar from subsonic to supersonic speed. Results were shown that the estimated wave drag through BOR has shown similar to 3D Navier Stokes (NS) aircraft simulation. Further, the drag estimated at subsonic and supersonic regimes for clean and store configuration has shown that the drag was predominant at supersonic regimes due to the cause of wave drag than at subsonic regimes. Therefore minimizing the wave drag play an essential for combat aircraft performance.

Several analytical [1, 2], experimental [3, 4] and numerical [5, 6] studies were made related to aerodynamic characteristics of fighter aircrafts for supersonic, transonic or subsonic regimes.

KEYWORDS: Drag, Wave Drag, CFD, Subsonic, Supersonic \& Combat Aircraft
\end{abstract}

Received: May 26, 2019; Accepted: Jun 17, 2019; Published: Jul 11, 2019; Paper Id.: IJMPERDAUG201984

\title{
INTRODUCTION
}

For combat aircraft to persists a better performance with less fuel consumption, it necessitate for aircraft to be minimum drag. Therefore for each reduction of Count (i. e., $C_{D}=0.0001$ ) has enhances the flight performance with less fuel consumption. Further, reduction of each drag count caters two additional passengers of payload to attain the same performance for the required range. Hence, it is required an accurate prediction of drag at subsonic to supersonic regimes. At supersonic speed, it has more emphasis on wave drag prediction due to shock wave formation. Therefore initial study has been carried on BOR for clean and store configuration for an rough estimation of wave drag at supersonic regimes. Later, the N-S simulation has been performed for 3D aircraft 
between clean and store configurations

\section{OBJECTIVES AND CONSTRAINTS}

- The main objective is to predict the drag for combat aircraft between clean and store configuration and their affect on combat performance using CFD tools across Mach number regimes. The contraints include:

- CFD simulation were performed to assess the drag at zero angle of attack across Mach regimes.

- Drag predictions were carried on untrim conditions across Mach number regimes.

- Combat performance were evaluated using CFD methods.

\section{GEOMETRY}

The combat aircrafts with clean and store configuration were shown in below Figure 1 and Figure 2 Store configuration consists of Inboard drop tank, Mid board drop bomb, Outboard missile (Short range Air to Air (A-A)), and Tip missile (Medium range A-A).

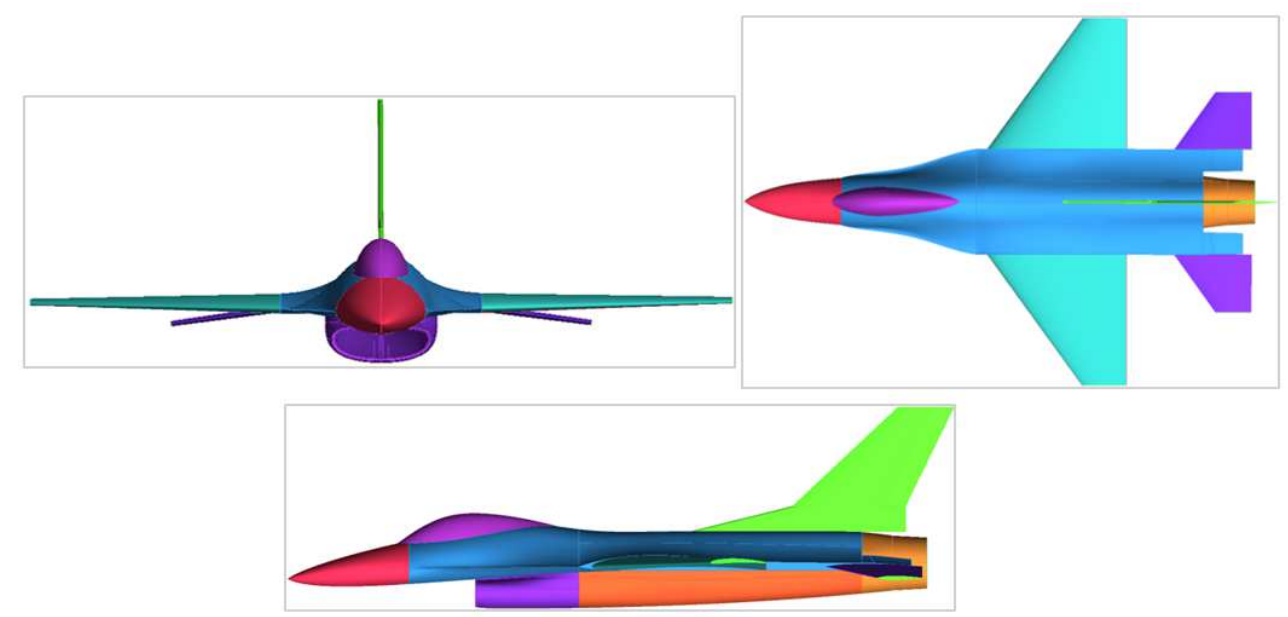

Figure 1: Combat Aircraft without Stores (Clean Aircraft)

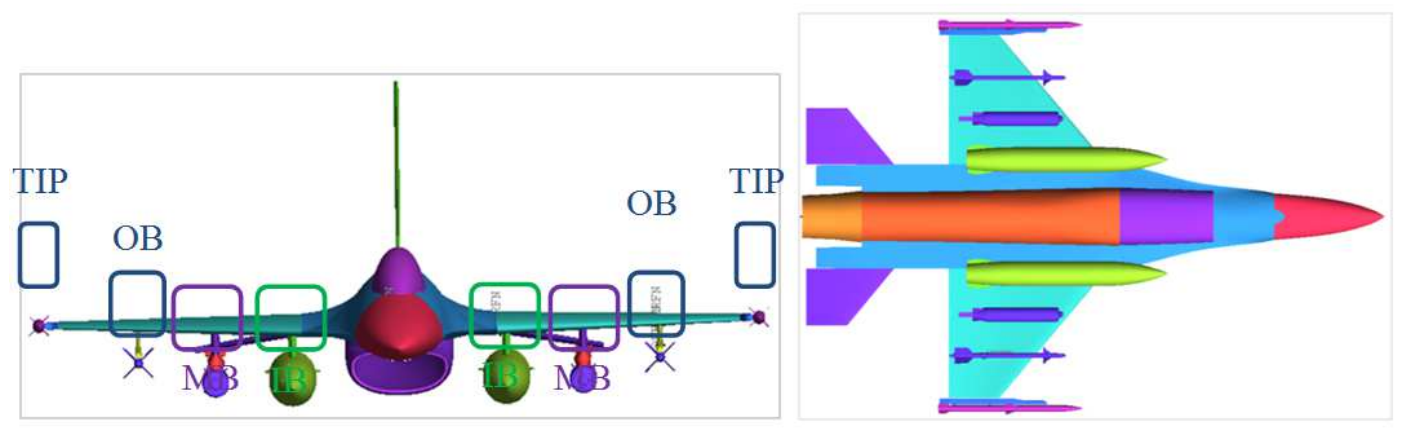

Figure 2: Combat Aircraft with Stores

\section{MESH}

Meshing is accomplished in ICEM CFD, Version 14.0-1. ICEM CFD is an Ansys tool used for modelling and meshing geometries. The reason for this tool selection is because it is simple and powerful, unstructured grid generation algorithm with good quality. For an accurate prediction of viscous, in viscid and flow separation flows, it was required an 
adequate grid density in volume was adopted based on previous experience in high speed flow simulations. Surface mesh (triangular elements) is shown in Figure 3. Unstructured volume mesh is shown in Figure 4, which has tetrahedron grid elements. Quadratic elements were generated in the prism layer to capture the growth of boundary layer near the wall. Mesh details were shown in below /Table 1.

Table 1: Mesh Details for Aircraft Store/Clean Configuration

\begin{tabular}{|l|c|}
\hline \multicolumn{2}{|c|}{ Mesh Details } \\
\hline Mesh Method & Unstructured \\
\hline Total Number Mesh elements $\left(\times 10^{6}\right)$ & 44 \\
\hline Total Number of Surface cells $\left(\times 10^{6}\right)$ & 1 \\
\hline Reynolds Number $\left(\times 10^{6}\right)$ & Flight conditions \\
\hline 1st Layer Height, mm & 0.0018 \\
\hline Prism Layers Growth rate & 1.25 \\
\hline Total height of Prism layers, $\mathrm{mm}$ & 35 \\
\hline
\end{tabular}

\section{NUMERICAL METHOD}

For CFD analysis, considered three dimensional ellipsoidal domain which was approximately 24 times the fuselage length along major axis and 15 times the fuselage length on minor axis. The far field set as inlet boundary conditions. No slip wall boundary conditions are imposed for combat aircraft. Below /Table 2/, provides boundary condition details for combat aircraft.

Table 2: Boundary Condition Details For Aircraft Store/Clean Configuration

\begin{tabular}{|l|c|}
\hline \multicolumn{2}{|c|}{ Solver details } \\
\hline Solver & CFD++ \\
\hline Mach number & 0.3 to 1.6 \\
\hline Turbulence model & SST \\
\hline Altitude (KM) & $0(\mathrm{M}=0.3$ to 0.95$) \& 1.5(\mathrm{M}>1)$ \\
\hline Total no Iterations & 2000 \\
\hline Global Residual set & $1 \mathrm{e}^{-8}$ \\
\hline AOA & 0 \\
\hline Turbulence viscosity value (fmu) & 10 \\
\hline
\end{tabular}

\section{RESULTS}

The drag prediction for combat aircraft design has been asssesed using BOR and 3D Navier stokes (NS) simulation for Clean and Store configuration. The drag predictions and their affect has been discussed below,

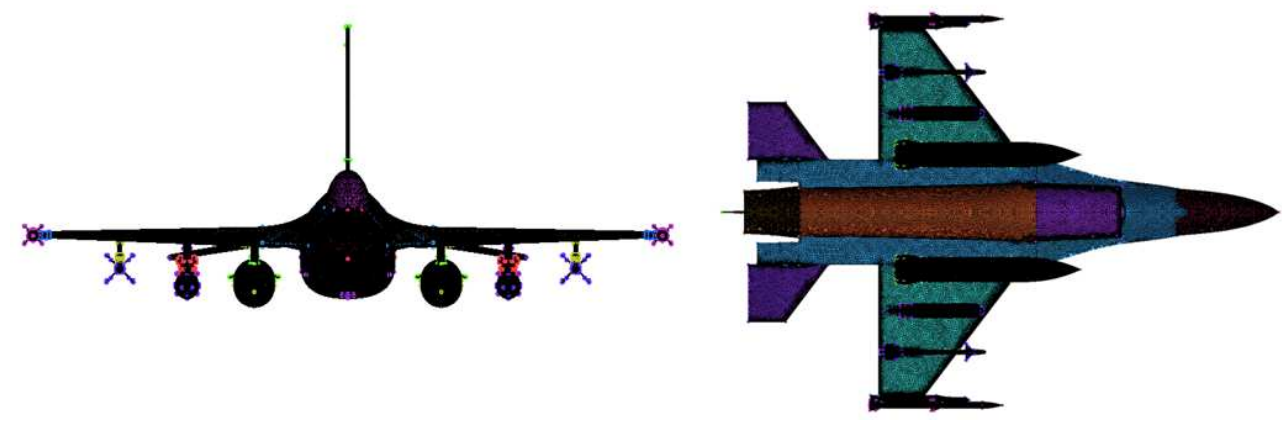

Figure 3: Surface Mesh on Combat Aircraft 


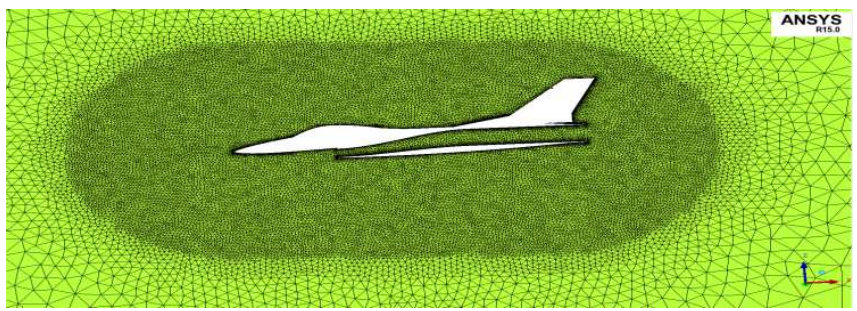

Figure 4: Unstructured Volume Mesh on Combat Aircraft with Stores

\section{BODY OF REVOLUTION (BOR)}

For initial study, BORs were carried out due to its fast and simple modelling, meshing and analysis instead on a full 3D aircraft. Wave drag is an equivalent body of revolution (BOR) of an aircraft, which has the same cross-section area distribution has taken normal to the flight direction. However non-linear effects such as shocks caused by local area variations (bumps, fairings, protuberances etc.) and interference effects (interaction of shocks caused by stores) are not reflected in BOR results and are captured only by investigating a full 3D aircraft. Thus it provides only a rough estimation of aircraft wave drag as a function of parametric changes to the aircraft area distribution. Hence, BORs has analyzed for one particular at $\mathrm{M}=1.2, \square=0$ for three Area distribution, as shown in Figure 4 and the results are tabulated in Table 3. BOR results shows that an ideal Area distribution provides a least drag for a given Area and Volume of an aircraft. However, in reality aircraft consists of undulation in area distribution as shown in Clean and Store configuration, which leads to more drag. Further, the drag raise is significant with stores configuration which is an almost double of an clean aircraft drag.

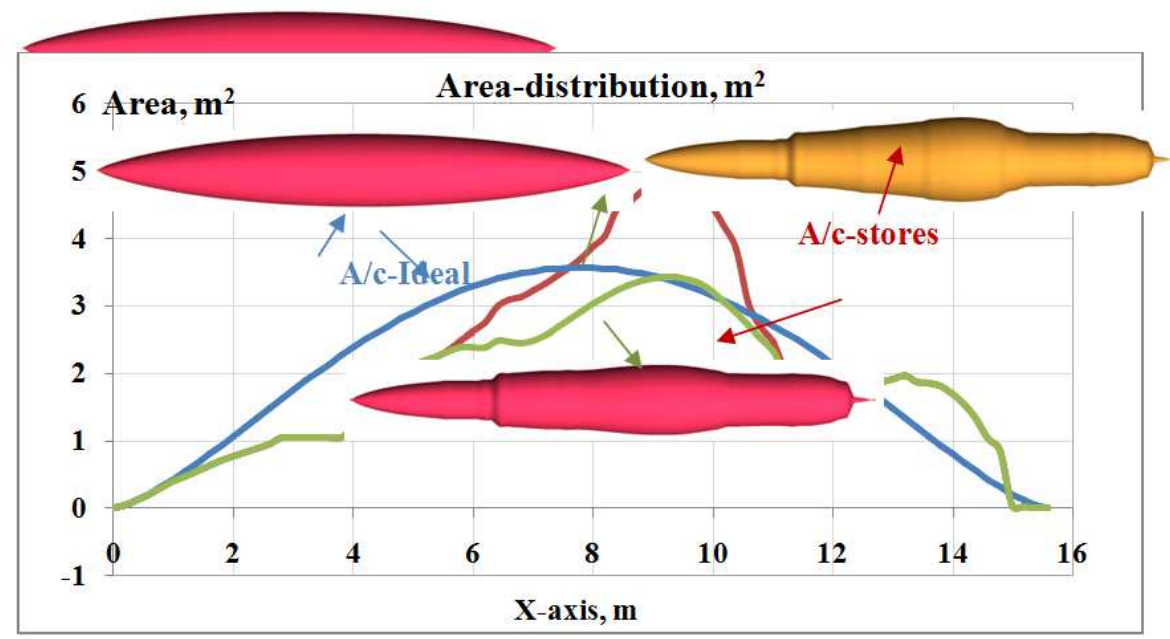

Figure 4: Area Distribution for Clean and Store Configuration

Table 3: BOR Results for Ideal, Clean, and Store Configuration

\begin{tabular}{|c|c|c|c|}
\hline S. No & \multicolumn{2}{|c|}{ BOR } \\
\hline & M & CD & CD \\
\hline Ideal & 1.2 & 0.0272 & Reference \\
\hline A/C with Clean & 1.2 & 0.0623 & 0.0351 (w. r. t Ideal) \\
\hline A/C with Store & 1.2 & 0.1015 & 0.0391 (w. r. t Clean) \\
\hline
\end{tabular}




\section{D-NS RESULTS}

The convergence history of residuals and drag has been shown in below Figure 5. It appears that the flow is smoothly converged to $10 \mathrm{e}-4$ and below.

\section{3d-Ns Results}

The drag for combat aircraft between clean and store configuration and their affect on combat performance using CFD tools across Mach number regimes has been asssesed.

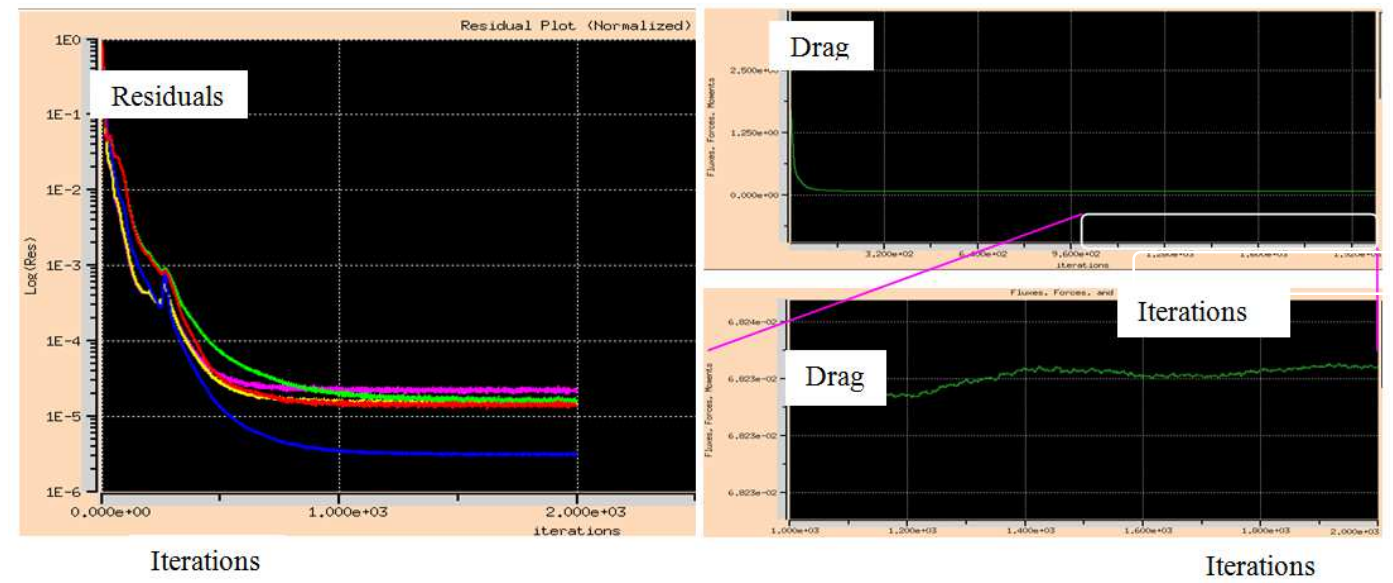

Figure 5: Convergence History of Residuals and Drag for Combat Aircraft

CD0: From Figure 6 both clean and stores configuration follows the same trend. As Mach number approach to sonic and supersonic conditions, the drag raise is significant and this is mainly due to the wave drag. The maximum drag occurs at Mach number 1.1, and it is due to the presence of normal shocks thereafter the drag raise is almost plateau with Mach number due to its vulnerable shock strength. Moreover, the stores configuration has significant raise in drag due to 4 armaments are installed in the wing which leads to more drag then clean configuration. The difference in drag raise between stores and clean is maximum apparently at supersonic speed than at subsonic speed due to wave drag. Therefore the CD0 is essential for designing combat aircraft to attain a good performance. CD vis: From Figure 7 it apparently appears that the viscous drag is not significant across Mach number regimes compared to pressure drag (i. e. inviscid drag). The maximum drag occurs at Supersonic speed, however the raise in drag is not significant than subsonic speed. Therefore the viscous drag is not essential as in viscid drag for designing combat aircraft. Further, the stores configuration has significant raise in drag than clean configuration due to 4 armaments are installed in the wing which attributes to viscous drag. $\mathrm{CD}_{\text {invis }}$ From Figure 8 both $\mathrm{CD} 0$ and CDINVIS are both follows the same trend. However the magnitude of CD0 is higher than CDINVIS, since in viscid drag is a subset of CD0.

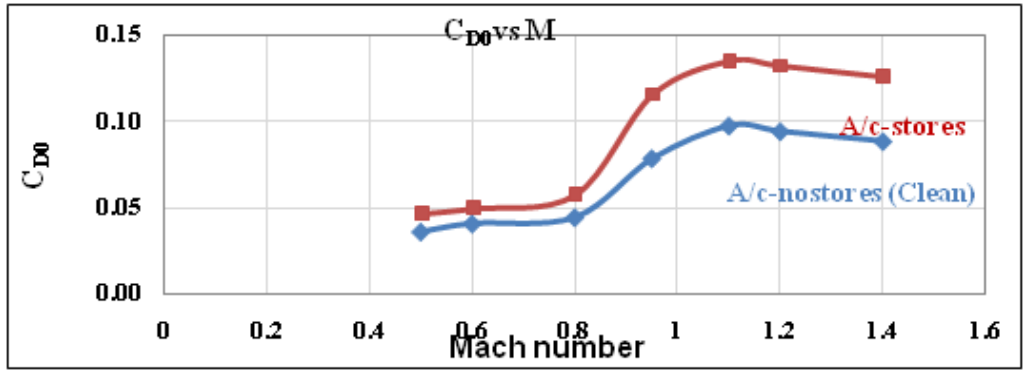

Figure 6: Zero Lift Drag Polar for Clean and Store Configuration 


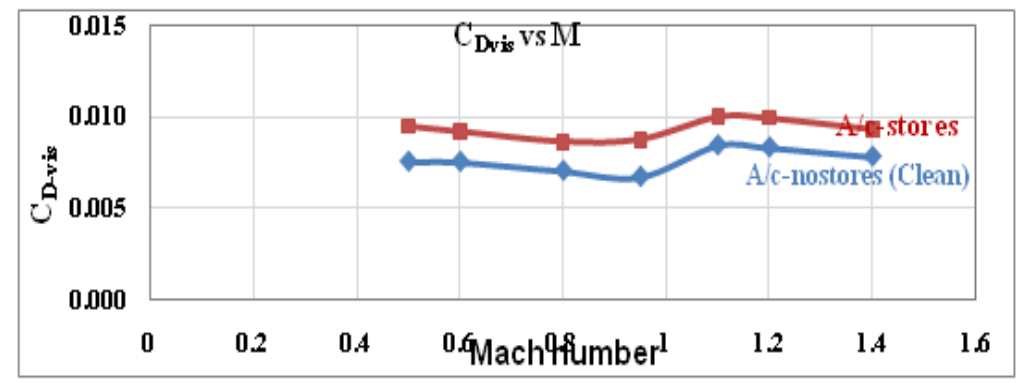

Figure 7: Viscous drag polar for Clean and Store Configuration

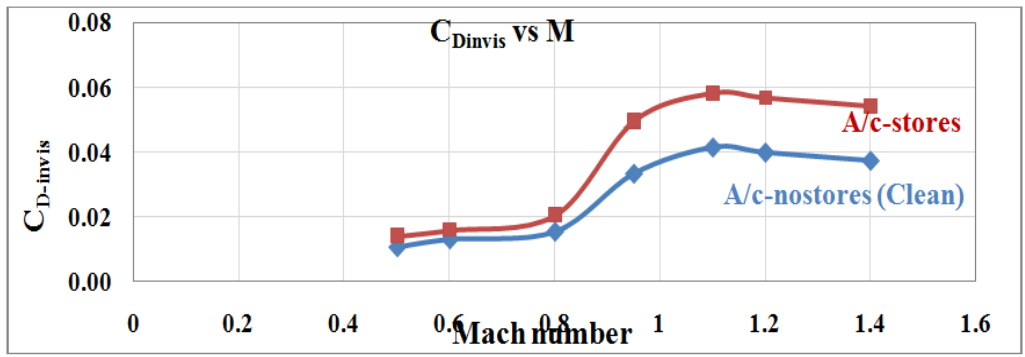

Figure 8: Inviscid Drag Polar for Clean and Store Configuration

\section{COMPARION BETWEEN BOR AND 3D NS}

\section{Clean Configuration}

The Coefficient of pressure and Mach number are shown in Figure 9 between BOR and 3D aircraft. Both BOR and 3D aircraft has shown nearly same flow characteristics in both pressure and Mach number contour. Since, BOR works on linear theory it captures shocks similar to 3D aircraft, however it doesn't capture the interaction effects as in 3D aircraft. Hence, BOR provides a rough estimation of drag for combat aircraft at supersonic speed in minimum turn around time.

\section{Store Configuration}

The Coefficient of pressure and Mach number are shown in Figure $\mathbf{1 0}$ between BOR and 3D aircraft. The flow characteristics between BOR and 3D aircarft are observed similar to Clean configuration for both pressure and Mach number contour. However the shocks are significant than clean configuration due to 4 arnaments are installed in the wing which attribute to more drag for store configuration.
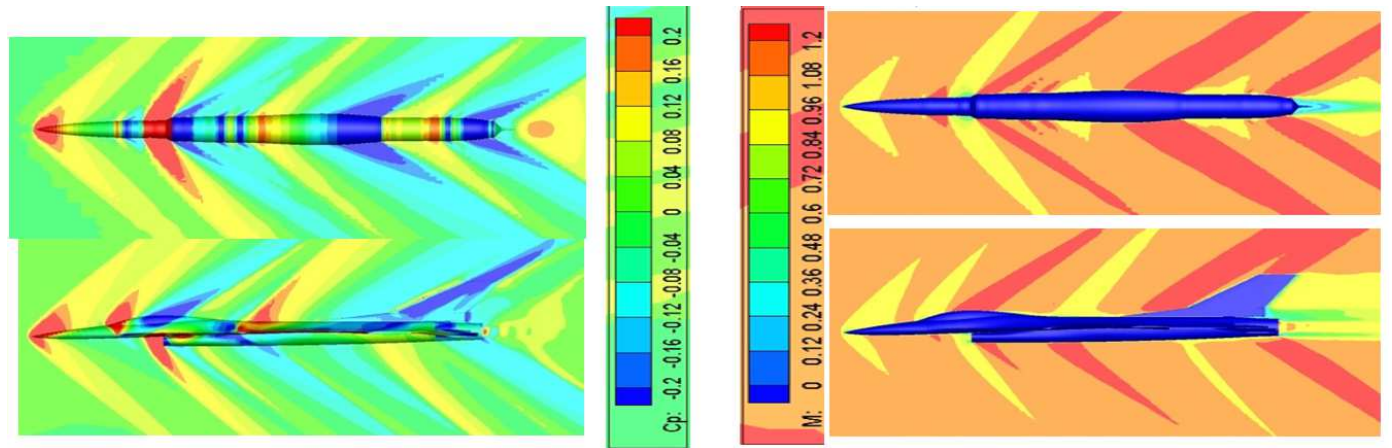

Figure 9: Pressure and Mach Contour between BOR and Clean Aircraft 

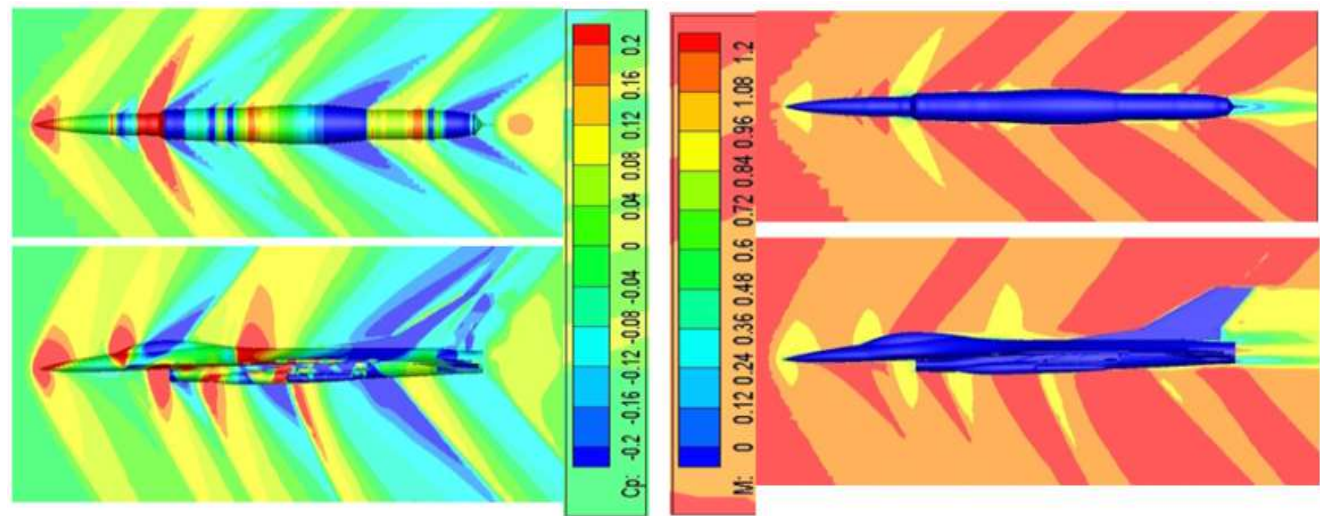

Figure 10: Pressure and Mach Contour between BOR and Store Configuration

\section{CONCLUSIONS}

- The conclusion drawn at subsonic and supersonic regimes for clean and store configuration has discussed below.

- The drag was predominant at supersonic regimes due to the cause of wave drag than at subsonic regimes. Therefore minimizing the wave drag play an essential for combat aircraft performance.

- BOR provides a rough estimation of wave drag in minimum turnaround time. Therefore, it facilitate the sensitivity of the design for combat aircraft performance.

- The zero lift drag obtained from 3D aircraft is provides an definite for clean and store configuration and their affect on combat aircraft performance.

- For Store configuration, it apparently has more drag than clean configuration due to 4 arnaments installed in the wing.

\section{ACKNOWLEDGEMENTS}

Authors are greatful to the supporting staff of DRDO (Srikanth U R, Muthuraj C)for providing assistance to carried out this research work.

\section{REFERENCES}

1. Ohad Gur, William H. Mason and Joseph A. Schetz, Full-Configuration Drag Estimation. Journal of Aircraft Vol.47, No 4 July-August 2010.

2. Charles A. Jobe, Prediction of Aerodynamic Drag, Air Force Right Aerodynamic Laboratories, July 1984.

3. Bowes, G. M., Aircraft Lift and Drag Prediction And Measurement. ACARD-LS-67, May 1974, Pp. 4-1 - 4-44.

4. C. W. Smith, J. N. Ralston, And H. W. Mann, Aerodynamic Characteristics Of Forebody And Nose Strakes Based On F-16 Wind Tunnel Test Experience, NASA Contractor Report 3053, July 1979

5. Manish Sharma, T. Ratna Reddy, Ch. Indira Priyadarsini, Flow Analysis Over And F-16 Aircraft Using Computational Fluid Dynamics: A Complete Work. International Journal Of Emerging Technology And Advanced Engineering. Volume 3, Issue 5, May 2013.

6. Dhawad, K., \& Patane, R. Speed Control Of 3-Ph Induction Motor With Two Stage IPFC Using 1-Ph Supply. 
7. Kyle D. Squires, James R. Forsythe And Scott A. Morton, William Z. Strang, Kenneth E. Wurtzler, And Robert F., Tomaro, Matthew J. Grismer, Philippe R. Spalart, Progress On Detached-Eddy Simulation Of Massively Separated Flows, Aerospace Sciences Meeting 14-18 January 2002.

8. Mullick, Bosu Sanjay. (2007). State Forest Policy And Adivasi Self Rule In Jharkhand. In Dr. Chittarajan Kumar Pathy (Ed.), Forest, Government And The Tribe, (Pp.2-29). New Delhi: Concept Of Publishing Company 